\title{
DIALÉTICA NEGATIVA: FILOSOFIA E METAFÍSICA - TENSÕES*
}

\author{
BRUno Puccl \\ Universidade Metodista de Piracicaba, Piracicaba, São Paulo, Brasil
}

RESUMO: Este ensaio se propõe a analisar o conceito de metafísica, desenvolvido por Theodor Adorno na Parte III, "Modelos", de seu livro Dialética negativa. Detém-se, a princípio, na abordagem da categoria dialética negativa, que se constitui no diálogo com Hegel; ao mesmo tempo, em contraposição à sua dialética idealista, toma como referência o pressuposto de que somente $o$ conceito pode ultrapassar o conceito e assim se aproximar do não conceitual. A seguir, à semelhança do processo anterior, denota o texto que o frankfurtiano, na construção de uma nova metafísica, não abandona as categorias específicas que historicamente lhe deram sustentabilidade, porém, inverte-as na tendência de sua direção: a metafísica negativa emigra para a micrologia, para "a escória do mundo dos fenômenos". No contexto da primazia do objeto sobre o sujeito, conceitos-chave da metafísica tradicional - essência, infinitude e profundidade - voltam-se, então, para "as coisas dos homens". O ensaio mostra, ainda, que Adorno, instigado pela observação de Simmel, de como é espantoso o quão pouco os sofrimentos da humanidade são observados na história da filosofia, construída em uma perspectiva idealista, se volta para a análise da dor, dos lamentos, do genocídio, tristes realidades que caracterizam a história dos homens em tempos de sociedades capitalistas.

Palavras-Chave: Dialética negativa. Metafísica. Theodor Adorno. Friedrich Hegel. 
Essa assertiva foi utilizada por Theodor Adorno, em seu ensaio Teoria da semiformação, de 1959, quando questionava os obstáculos culturais que o sistema capitalista de seu tempo impunha ao indivíduo na busca de sua autonomia, entre eles, o desprestígio da filosofia na educação formal. Aqui o autor se refere explicitamente à metafísica dos pensadores do idealismo alemão, Humboldt, Scheleiermacher, Fichte, Hegel. O predomínio da visão positivista, bem como da onipotência do espírito alienado fizeram com que a formação cultural se convertesse em uma semiformação generalizada e, com isso, a "irrevogável queda da metafísica", o esmagamento da Bildung. Adorno volta a utilizar a expressão "queda da metafísica" ao término de seu livro Dialética negativa, de 1966, quando diz: "um pensamento (que não se fecha sobre si mesmo e se joga a fundo perdido nos objetos, bp) é solidário com a metafísica no instante de sua queda" (ADORNO, 2009, p. 337).

O livro Dialética negativa, recentemente traduzido para a língua portuguesa, 2009, é composto de um breve Prefácio, de uma longa Introdução (26 parágrafos) e de três partes. Na primeira, Adorno dialoga com Heidegger, o principal filósofo de seu tempo, em dois tópicos: "Relação com a ontologia" e"Ser e existência". Na segunda parte, discorre sobre o conceito e as categorias da dialética negativa. E na terceira, apresenta três modelos de análise da dialética negativa, dialogando: $1 .{ }^{\circ}$ ) com Kant, em especial, sobre a "Liberdade"; $2 .{ }^{\circ}$ ) de forma particular com Hegel, sobre "O espírito do mundo e história natural"; e 3.०) com a metafísica dos idealistas alemães , em "Meditações sobre a metafísica". O livro todo foi escrito em forma de aforismos, de pequenos ensaios filosóficos. A solidariedade da dialética negativa com a metafísica perpassa o livro todo, permeada de tensões, fricções; é uma solidariedade negativa, crítica. Mas é no terceiro modelo que ela se torna explícita. Depois de argumentar que aquilo que precisa ser conhecido, o objeto, se assemelha antes ao que se encontra tetê-a-tete do que a algo que se eleva além da vista, complementa:

É para tal verdade diversa que se dirige a provocação de que a metafísica só poderia vencer se rejeitasse a si mesma. Isso motiva efetivamente sua passagem para o materialismo. Podemos seguir essa inclinação desde o Marx hegeliano até a salvação benjaminiana da indução; sua apoteose poderia ser a obra de Kafka. Se a dialética negativa reclama a autorreflexão do pensamento, então isso implica manifestamente que o pensamento também precisa, para ser verdadeiro, hoje em todo caso, pensar contra si mesmo. Se ele não se mede pelo que há de mais exterior e que escapa ao conceito, então ele é de antemão marcado pela música de acompanhamento com a qual os SS adoravam encobrir os gritos de suas vítimas. (ADORNO, 2009, p. 302) 
A Dialética negativa, a um só tempo, se constitui no diálogo com Hegel e se contrapõe à sua dialética idealista. À semelhança de Hegel, a negação é a mediação fundamental na passagem de um momento a outro, no processo da constituição do conhecimento. Em contraposição a Hegel, a permanência na negatividade adia a síntese por tempo indeterminado: "A filosofia, que um dia pareceu ultrapassada, mantém-se viva porque se perdeu o instante de sua realização. [...] Talvez não tenha sido suficiente a interpretação que prometia a transição prática" (2009, p. 11). Em conformidade a Hegel, é através do conceito que o sujeito conhece o objeto, pois o instrumental de intervenção da filosofia são os conceitos. Em oposição a ele, o conceito, mesmo sendo uma "adequatio rei et intelectus",1 como dizia a filosofia tradicional, não consegue captar o objeto em sua plenitude, por ele ser universal, abstrato, formal; o objeto, representado por Adorno, é particular, concreto, histórico: "A dialética é a consciência consequente da não identidade" (ADORNO, 2009, p. 13) entre conceito e objeto. E porque o conceito é a tentativa frustrada de o sujeito se identificar com o seu não outro, o objeto, a filosofia, padece de uma enorme ingenuidade: "saber quão pouco alcança o que é pensado e, no entanto, falar como se o possuísse inteiramente" (p. 21). A dialética, na teimosia de seu momento negativo, é a tentativa de extinguir o suposto poder autárquico do conceito, arrancando-lhe dos olhos as vendas (p. 19). E, ao mesmo tempo que atesta a fragilidade do sujeito em seu objetivo específico, estimula-o a ir além de si mesmo, em busca daquilo que, no processo de conhecimento, foi reprimido, desprezado, ignorado: "Para o conceito, o que se torna urgente é o que ele não alcança, o que é eliminado pelo seu mecanismo de abstração, o que deixa de ser um mero exemplar seu" (p. 15). Simultaneamente, essa dialética, que prioriza o objeto, que desnuda o sujeito, que atesta a fragilidade do conceito, de forma mais intensa do que nunca, precisa da insistência do sujeito: "Em uma oposição brusca ao ideal de ciência corrente, a objetividade de um conhecimento dialético precisa de mais, não de menos sujeito. Senão, a experiência filosófica definha" (p. 42).

Em outras palavras, a filosofia só pode realizar o empreendimento de ir além do conceito através do próprio conceito. Essa é a expressão-chave que sustenta os aforismos da Dialética negativa, em suas infindáveis variantes. Cito algumas: "o conceito pode ultrapassar o conceito e assim aproximar-se do não conceitual" (ADORNO, 2009, p. 16); "A utopia do conhecimento seria abrir o não conceitual com conceitos" (p. 17); "Os conceitos - mesmo o de Ser da lógica hegeliana - visam algo para além de si mesmos” (p. 18); "A reflexão filosófica assegura-se do não conceitual no conceito" (p. 19); "Na nostalgia (que anima a arte como algo não conceitual - bp) reside o esforço de ir além do conceito por meio do conceito" (p. 22); "Lá onde o pensamento se projeta para 
além daquilo a que, resistindo, ele está ligado, acha-se a sua liberdade" (p. 24); "Somente os conceitos podem realizar aquilo que o conceito impede" (p. 53).

Theodor Adorno ressalta, na Dialética negativa, as afinidades e as íntimas relações entre o sistema filosófico idealista e a realidade natural e social em que esse se constitui: o sistema capitalista em seus inícios na Alemanha. Adorno estava convencido de que as contradições sociais aparecem no interior do material da filosofia em forma mediada. Assim, o sistema filosófico idealista, no qual o espírito soberano se imaginava transfigurado no espírito absoluto, tem a sua história primordial no elemento pré-espiritual, na vida animal da espécie. O sistema é famélico como os animais predadores: tudo quer devorar, tudo quer enquadrar; nada pode ficar de fora, ser alheio a ele. Diz Adorno: "O sistema é o ventre que se tornou espírito, a fúria é a marca registrada de todo e qualquer idealismo". E ainda mais, há um contraponto entre o sistema filosófico e o processo social: "Enquanto princípio de troca, a ratio burguesa realmente assimilou aos sistemas, com um sucesso crescente, ainda que potencialmente assassino, tudo aquilo que queria tornar comensurável a si mesma, identificar consigo, deixando sempre cada vez menos de fora" (2009, p. 28). O sistema capitalista, para sobreviver, também precisa continuamente se reproduzir, transformar tudo em mercadoria; nada Ihe pode ficar alheio. Essa mesma ideia é retomada páginas à frente, quando diz que o idealismo, através da ratio, transforma a constituição do pensamento, sua autonomização histórica, em metafísica.

Ele elimina todo ente heterogêneo [...]. A antinomia da totalidade e da infinitude [...] é uma antinomia da essência idealista. Ela reproduz uma antinomia central da sociedade burguesa. Essa também precisa, para conservar a si mesma, para permanecer idêntica a si mesma, para "ser", expandir-se continuamente, prosseguir, lançar sempre para mais além os limites, não respeitar nenhum deles, não permanecer igual a si mesma. (ADORNO, 2009, p. 30-33)

No aforismo "Conteúdo e método", ainda na Introdução da Dialética negativa, Adorno afirma que "Conceito e realidade possuem a mesma essência contraditória. Aquilo que dilacera a sociedade de maneira antagônica, o princípio de dominação, é o mesmo que, espiritualizado, atualiza a diferença entre o conceito e aquilo que lhe é submetido" (p. 49). E no aforismo "A resignação kantiana", nas "Meditações sobre a metafísica", argumenta que a estrutura antinômica do sistema kantiano expressa mais do que contradições, nas quais se enredaria a especulação sobre objetos metafísicos; expressa, também, algo histórico-filosófico:"nele se repete a transformação da burguesia, a transformação de uma classe revolucionária para a classe conservadora" ( $p$. 318). Essas constantes aproximações entre a metafísica idealista e a sociedade 
burguesa, na qual e em razão da qual aquela foi constituída, nos atestam que as categorias metafísicas, por mais abstratas e universais que sejam, por mais disfarçadas que se apresentem, tornaram-se o que são no confronto com o objeto real, concreto, histórico e a ele devem sua sobrevivência e perenidade. $E$, se quiserem continuar sendo categorias metafísicas, devem reconhecer esse fato e se aproximarem, cada vez mais, dos objetos que as constituem.

No início de nosso texto, trouxemos uma longa citação de Adorno, que diz que a metafísica só poderia vencer e evitar sua queda se rejeitasse a si mesma, se efetivasse sua passagem para o materialismo, para a priorização do objeto. E que, para atingir esse objeto, o pensamento negativo, pela autorreflexão, precisa pensar contra si mesmo, medir-se pelo que lhe é heterogêneo e lhe escapa. Adorno traz outras variantes para reforçar essa ideia:

Aquilo que se retrai torna-se cada vez menor, cada vez menos aparente; esse é o fundo crítico-cognitivo tanto quanto histórico-filosófico do fato de a metafísica ter emigrado para a micrologia. A micrologia é o lugar da metafísica como refúgio diante daquilo que é total. (ADORNO, 2009, p. 337)

Micrologia, para Houaiss, significa "a importância excessiva que se dá a coisas insignificantes". A metafísica não é mais possível como uma conexão dedutiva de juízos sobre o ente. É para as coisas aparentemente insignificantes (Houaiss), para "a escória do mundo dos fenômenos" (Freud), para a observação do particular concreto (Benjamin) que se deve voltar a metafísica, sem abandonar as categorias específicas que Ihe deram sua sustentabilidade histórica, porém, "invertidas na tendência de sua direção”. Diz Adorno: "Quando uma categoria se transforma - por meio da dialética negativa, a categoria da identidade e da totalidade -, a constelação de todas as categorias se altera e, com isso, uma vez mais cada uma delas" (2009, p. 144). Já vimos, quando comparamos a dialética idealista com a dialética negativa, que o conceito de "identidade" (o ideal é o real e vice-versa) é falso, pois o objeto não se sente representado pelo seu conceito de forma plena, e nem esse se sente suficientemente contemplado em seu objeto; o que prevalece é o conceito da "não identidade" entre o objeto e sua representação abstrata. A dialética negativa questiona também o conceito de totalidade hegeliano, como se em suas entranhas estivesse contido tudo o que ele diz abranger. Para Adorno, "o todo é o não verdadeiro" (1992, p. 42), "o totum é o totem" (2009, p. 313). Vamos analisar a "inversão" de apenas três categorias metafísicas pela dialética negativa: essência, infinitude e profundidade. Essas categorias provêm da tradição filosófica, mas são convertidas na tendência de outra direção.

Adorno interpreta a categoria "essência" em um dos aforismos da Parte II, “Dialética negativa: conceito e categorias". A essência - aquilo em 
virtude do qual alguma coisa é o que é; o quid, na perspectiva aristotélicotomista - não pode mais ser absolutizada como um puro ser-em-si espiritual, como o momento exclusivo da subjetividade no objeto, como um produto do conhecimento no qual esse sujeito mesmo se encontra, uma vez mais, confirmado em sua função definidora de limites. Ao invés disso, a essência só pode ser reconhecida na contradição entre o que a coisa é e o que afirma ser; ela exprime o fato de o sujeito se dirigir sempre ao objeto, ao mundo que lhe é contraposto, para que esse lhe diga o que ele é. A essência não é, pois, apenas produto de sínteses e abstrações; ela representa, sobretudo, um mergulho contínuo do sujeito no múltiplo, na história do não idêntico e, nesse sentido, a essência também ganha conotações históricas. Um objeto não é sempre aquilo que é; ele também já foi e um dia será. É no confronto dialético entre sujeito e objeto que ela vai se manifestando."A essência lembra da não identidade no conceito daquilo que não é posto pela primeira vez pelo sujeito, mas ao que ele segue", reforça o frankfurtiano. É o momento ôntico que se reproduz nas categorias, e não o inverso. O positivismo - que questiona a metafísica da essência e que, por sua vez, se detém na aparência - transforma-se em ideologia, alijando a categoria objetiva da essência e, por consequência o seu interesse pelo essencial. Para Adorno, "contestar que haja uma essência significa se colocar do lado da aparência, da ideologia total na qual entrementes a existência se transformou". É a visão que se volta para o "resíduo do mundo das aparências", que dirige o olhar para o particular, considerado como o não idêntico, como síntese de múltiplas determinações (Marx), para o que foi expelido para a margem, que mais condições tem de se aproximar da essência, do que é essencial. "O essencial tanto é amplamente contrário à universalidade dominante, à inessência, quanto a supera criticamente" (2009, p. 144-147).

A categoria "infinitude" também é invertida "na tendência de sua direção". Em um dos aforismos da Introdução, intitulado "Infinitude" (2009, p. 19-22), Adorno tece considerações sobre a ideia de infinito corrompida pelo idealismo, quando se vangloria da capacidade de o conceito captar o objeto de forma ilimitada, exaustiva, abrangente, produzindo a identidade entre o que representa e o que é representado. É preciso refuncionalizar essa ideia legada pelo idealismo; é preciso desmitologizar o conceito, impedir seu supercrescimento; que ele continue absoluto. A filosofia quer mergulhar a fundo perdido no que lhe é heterogêneo, mas sabe de suas limitações, conhece a precariedade de seu instrumento de intervenção, qual seja o conceito: "O conhecimento não possui nenhum de seus objetos completamente. Ele não deve promover o aparecimento do fantasma do todo" (2009, p. 20). Contudo - e aqui Adorno retoma as aspirações dos românticos 
alemães -, o infinito, enquanto impossível, continua sendo o ideal da filosofia; ela quer de tal forma aproximar o conceito do objeto, de modo a desfazer a diferença entre um e outro, e sofre de tristeza (nostalgia) por não conseguir realizar essa infinitude. Mas ela não desiste e, em sua trajetória, como faziam os românticos alemães, vai buscar - no lúdico na mímesis, no momento estético, no momento somático, no momento especulativo - afinidades ilimitadas entre o conceito e o objeto; aproxima-se da arte, mas sem deixar de ser filosofia: "O conceito não consegue defender de outro modo a causa daquilo que reprime, a da mimesis, senão na medida que se apropria de algo dessa mimesis em seu próprio modo de comportamento, sem se perder nela" (2009, p. 21). Então, o infinito, visto pelo idealista, desenha o fetiche do conceito; visto na proximidade dos elementos não conceituais, transformase em uma aspiração possível. "Para ser espírito, o espírito precisa saber que não se esgota naquilo que alcança; que não se esgota na finitude com a qual se assemelha. Por isso, ele pensa o que lhe seria subtraído" (2009, p. 325).

E o que dizer sobre a categoria "profundidade", presente de maneira enfática até na conceituação metafísica de filosofia? Expressões como "análise em profundidade", "a filosofia como a busca de causas profundas", "o sentido profundo do ser" e outras são questionadas por Adorno. Na conferência "A atualidade da Filosofia", quando ingressou como professor na Universität Johann W. Goethe, de Frankfurt, em 1931, Adorno argumenta que a função da filosofia é interpretar os acontecimentos humanos, para construir maneiras diferentes de se enxergar esses mesmos acontecimentos. Interpretar, para ele, não se confunde com a busca de um "sentido oculto", como se a realidade estivesse plena de sentido a ser desvendado; não é tarefa da filosofia "demonstrar nem justificar tal sentido como dado positivamente". O conceito de interpretação não afirma a existência de algo encoberto atrás do fenômeno que se torna acessível pela análise e transcendência. Não há um sentido pronto e permanente por detrás da questão a ser descoberta pela análise filosófica. Antes, a interpretação se processa como na solução de um enigma, quando os elementos singulares e dispersos da questão são colocados em diferentes formas de ordenação, até que se juntam em uma figura, em uma imagem que ilumina a questão e descortina sua resolução. Da mesma maneira, a filosofia tem de dispor os esparsos elementos do real, que a ciência ou a experiência lhe proporcionam, em diferentes tentativas de ordenação, até que eles se projetem em uma figura legível como resposta, enquanto, simultaneamente, a questão desaparece. Diz Adorno:

Não é tarefa da filosofia investigar intenções ocultas e preexistentes da realidade, mas interpretar uma realidade carente de intenções, mediante a 
capacidade de construção de figuras, de imagens, a partir dos elementos isolados da realidade. (ADORNO, 2000, p. 8-9)

Metáfora símile é contemplada na Parte ll da Dialética negativa, agora em 1966, ao argumentar que o conhecimento do objeto em sua constelação (Cf. PUCCl, 2012a, p. 9) é o conhecimento do processo que ele acumula em si:

Enquanto constelação, o pensamento teórico circunscreve o conceito que ele gostaria de abrir, esperando que ele salte, mais ou menos como os cadeados de cofres-fortes bem guardados: não apenas por meio de uma única chave ou de um único número, mas de uma combinação. (Aforismo "Constelação", ADORNO, 2009, p. 142)

E no aforismo "Momento especulativo", na Introdução da Dialética negativa, ao defender a importância da especulação na experiência filosófica, Adorno traz mais alguns elementos sobre o que entende por profundidade. "A filosofia só toma parte na ideia de profundidade em virtude de sua respiração pensante. [...] A profundidade também é um momento da dialética, e não uma qualidade isolada, como não escapou a Hegel" (2009, p. 23). Para o autor, a dignidade do pensamento não é decidida por seu resultado, pela confirmação da transcendência, ou mesmo pela sua imersão na interioridade, como se a retirada do mundo dos objetos coincidisse com a consciência do fundamento do mundo. Antes:

Em contraposição aos fantasmas da profundidade que, na história do espírito, sempre se deram muito bem com aquilo que existe [...], a resistência seria a verdadeira medida da profundidade. O poder do existente erige as fachadas contra as quais se debate a consciência. Essa deve ousar atravessá-las. Somente isso arrancaria o postulado da profundidade à ideologia. $\mathrm{O}$ momento especulativo sobrevive em tal resistência. (ADORNO, 2009, p. 23)

Como se vê, Adorno não abandona esse conceito tão caro à metafísica tradicional; recupera-o em uma outra perspectiva, na qual o sujeito se torna ainda mais atuante que em Kant e Hegel, pela intervenção firme e permanente na história dos objetos que com ele se confrontam.

Se a dialética negativa se caracteriza pela tensa relação entre sujeito e objeto; se o objeto que se confronta com o sujeito outra coisa não é senão as contradições da sociedade capitalista em que vivemos; se a dominação, a desigualdade, a injustiça, enfim, o sofrimento são as expressões mais profundas e agudas dessa sociedade, desse objeto do conhecimento; por que o sofrimento humano, que é físico, corporal, foi tão sufocado na história da filosofia? São questões que a Dialética negativa nos coloca, doloridamente, ao desfolhar suas páginas. Assim no aforismo "Realidade e dialética", Adorno 
reafirma que essa não é apenas uma lei do pensamento, ela é uma lei do real. E que "o que há de doloroso na dialética é a dor em relação a esse mundo, elevada ao âmbito do conceito". Sendo assim, "o conhecimento precisa se juntar a ele - ao conceito (bp) - se não quiser degradar uma vez mais a concretude ao nível da ideologia; o que realmente está começando a acontecer" (2009, p. 13-14). Mais à frente, nos mostra que se, de um lado, o pensamento encontra sua liberdade quando se projeta em direção ao objeto que lhe resiste, por outro, "a necessidade de dar voz ao sofrimento é condição de toda verdade". "Pois (continua o texto) sofrimento é objetividade que pesa sobre o sujeito, aquilo que ele experimenta como seu elemento mais subjetivo, sua expressão" (2009, p. 24). Já no aforismo "Objetividade e contradição", na Parte II, a Dialética Negativa nos traz, com consternação, um imperativo: "o pudor ordena à filosofia não reprimir a intelecção de Georg Simmel, segundo a qual é espantoso o quão pouco os sofrimentos da humanidade são observados na história da filosofia" (2009, p. 133).

Quase ao final da Parte II, em que expõe o conceito de dialética negativa e as categorias que a constituem, Adorno dedica um aforismo inteiro para falar da dor: "O sofrimento é físico" (2009, p. 172-174). Algumas citações do aforismo:

Toda a dor e toda negatividade, motor do pensamento dialético, se mostram como figura multiplamente mediatizada, e, por vezes, irreconhecível do elemento físico, assim como toda felicidade visa ao preenchimento sensível e conquista nesse preenchimento sua objetividade. (2009, p. 173)

Se a negatividade é o motor da dialética no âmbito da subjetividade, do espírito, tanto em Hegel quanto em Adorno, a dor deveria ser o motor da dialética na transformação da realidade; o que não o é em Hegel, pois ela é diluída pelo espírito. No entanto, a negatividade do pensamento só é possível a partir da negatividade do sofrimento. E nela está a possibilidade de sua supressão.

O mínimo rastro de sofrimento sem sentido experimentado no mundo infringe um desmentido a toda a filosofia da identidade que gostaria de desviar a consciência da experiência:"Enquanto ainda houver um mendigo, ainda haverá mito"; é por isso que a filosofia da identidade é, enquanto pensamento, ideologia. O momento corporal anuncia ao conhecimento de que o sofrimento não deve ser, de que ele deve mudar. (2009, p. 173)

Identificar o espírito absoluto (afirmação suprema da realização da razão e da humanidade) com o espírito objetivo (o mundo de dor e sofrimento dos homens) é falsidade, é ideologia para a dialética negativa; é 
como enxergar, no princípio de troca da sociedade capitalista, a igualdade entre os que realizam a troca e entre os produtos trocados. De um lado, o mínimo resquício de dor, de sofrimento entre os mortais é um desmentido à afirmação de identidade; enquanto houver um mendigo no mundo, haverá desigualdade social, prevalecerá a não identidade, predominará o mito e não o esclarecimento; por outro lado, o sofrimento, enquanto manifestação imediata do corporal, é o anúncio expressivo, a exigência de que se deve mudar. "Por isso - continua o frankfurtiano -- o especificamente materialista converge com aquilo que é crítico, com a práxis socialmente transformadora" (2009, p. 173). Ou seja, a dialética negativa materialista - ou se quiserem, a metafísica negativa adorniana - expressa, filosoficamente, a perspectiva social transformadora que ela carrega em suas entranhas, em sua negatividade extrema. A sociedade poderia ser estruturada de outra maneira que a organização vigente, pois, o estágio atual das forças produtivas, aqui e agora, o permitem.

Uma tal organização teria o seu telos na negação do sofrimento físico ainda do último de seus membros e nas formas de reflexão intrínsecas a esse sofrimento. Ela é o interesse de todos e não é paulatinamente realizável senão por uma solidariedade transparente para ela mesma e para todo vivente. (2009, p. 174)

E, por falar em dor, em sofrimento, expressões mais profundas e agudas da sociedade dos homens, Adorno introduz a III Parte da Dialética negativa, "Meditações sobre a metafísica", com o aforismo "Depois de Auschwitz" (Cf. PUCCI, 2012b, p. 9). Auschwitz, o paradigma da dor, do sofrimento, do genocídio, em que não foram indivíduos que morreram e, sim, espécimes; diante de Auschwitz, "a faculdade metafísica é paralisada porque o que aconteceu destruiu para o pensamento metafísico especulativo, a base de sua unificabilidade com a experiência" (ADORNO, 2009, p. 299).

O doloroso estigma que pesa sobre a cultura "depois de Auschwitz" - essa refinada cultura burguesa alemã que propiciou o acontecimento do holocausto - surge na filosofia negativa de Theodor Adorno em diversos momentos e, sempre, de modo angustiante; como o persistente sobressalto do judeu que deveria ter sido assassinado no campo de concentração e que, por circunstâncias, não o foi, enquanto milhões de outros o foram em seu lugar.

No primeiro momento do ensaio Crítica cultural e sociedade, de 1949 - em que o autor questiona os críticos profissionais da cultura, na Alemanha de sua época -, Adorno propõe, em contraposição à chamada crítica cultural externa e ideológica, uma crítica dialética, imanente. E, ao final de seu texto, retoma a relação da cultura com a barbárie: 
A crítica cultural defronta-se com o último degrau da dialética entre cultura e barbárie: é barbárie escrever um poema depois de Auschwitz, e isso também corrói o conhecimento que afirma por que hoje se tornou impossível escrever poemas. Enquanto o espírito crítico permanecer em si mesmo, em autossuficiente contemplação, ele não será capaz de enfrentar a absoluta reificação que, entre os seus pressupostos, teve o progresso do espírito como um dos seus elementos e que hoje se prepara para sugá-lo completamente. (ADORNO, 1998, p. 26)

O segundo momento, em ordem temporal, localiza-se na Dialética negativa, de 1966, no aforismo "Depois de Auschwitz", o primeiro das "Meditações sobre a metafísica". Para o frankfurtiano, persiste a sensação de que, depois de Auschwitz, toda afirmação de positividade da existência ( $a$ vida é bela) é um ato de injustiça contra as vítimas do Progom. Utiliza-se ele dessa argumentação porque, enquanto judeu que é, continua sentindo na pele a dor contínua pelo que aconteceu com os seus idênticos? Certamente que sim; mas também porque, apesar do que aconteceu, a frieza burguesa, a indiferença pelo não idêntico, continua alimentando o esquecimento das tragédias e preparando condições para que outras aconteçam. É o pesar estampado na afirmação que se segue:

O sofrimento perenizante tem tanto direito à expressão quanto o martirizado tem de berrar; por isso é bem provável que tenha sido falso afirmar que depois de Auschwitz não é mais possível escrever nenhum poema. Todavia, não é falsa a questão menos cultural de saber se ainda é possível viver depois de Auschwitz, se aquele que por acaso escapou quando deveria ter sido assassinado tem plenamente o direito à vida. Sua sobrevivência necessita já daquela frieza que é o princípio fundamental da subjetividade burguesa e sem a qual Auschwitz não teria sido possível: culpa drástica daquele que foi poupado. (ADORNO, 2009, p. 300)

O terceiro momento incisivo de crítica à cultura depois de Auschwitz aparece no pequeno ensaio de 1967, A arte é alegre, publicado no IV livro das Notas de literatura. O judeu, angustiado, continua a debater consigo mesmo se é possível a arte - enquanto "crítica da feroz seriedade que a realidade impõe aos seres humanos" e, ao mesmo tempo, "promesse de bonheuer", utopia de uma nova realidade - ser alegre depois do que aconteceu em Auschwitz. Argumenta ele:

A arte, que não é mais possível se não for reflexiva, deve renunciar por si mesma a alegria. $A$ isso é forçada pelo que aconteceu recentemente. $A$ afirmativa de que após Auschwitz não é mais possível escrever poema não deve ser cegamente interpretada, mas com certeza depois que Auschwitz 
se fez possível e que permanece possível no futuro previsível, a alegria despreocupada na arte não é mais concebível. Objetivamente se degenera em cinismo, independente de quanto se apoie na bondade e na compreensão. (ADORNO, 2001, p. 15-16)

Por outro lado, o doloroso estigma "depois de Auschwitz" impõe aos homens do século XX - e, por que não dizer, do século XXI - um novo imperativo categórico, à semelhança do que Kant expressou na Crítica da razão prática: que Auschwitz não se repita! Esse imperativo irrefutável é expresso, de forma enfática, em dois momentos de seus escritos. Primeiramente, no ensaio educacional Educação após Auschwitz, apresentado na Rádio de Hessen, em 1965. Diz o frankfurtiano:

Para a educação, a exigência que Auschwitz não se repita é primordial. [...] Todo debate sobre parâmetros educacionais é nulo e indiferente em face deste - que Auschwitz não se repita. Ela foi a barbárie contra a qual se dirige toda a educação. Fala-se na iminente recaída na barbárie. Mas ela não é iminente, Auschwitz é a própria recaída; a barbárie subsistirá enquanto as condições que produziram aquela recaída substancialmente perdurarem. É isso que apavora. (ADORNO, 2003, p. 119)

O segundo momento acontece no aforismo "Metafísica e cultura", das Meditações sobre a metafísica. E aqui, Adorno é mais enfático ainda:

Em seu Estado de não liberdade, Hitler impôs aos homens um novo imperativo categórico: instaurai o vosso pensamento e a vossa ação de tal modo que Auschwitz não se repita, de tal modo que nada desse gênero aconteça. Esse imperativo é tão refratário à sua fundamentação quanto outrora o dado do imperativo kantiano.Tratá-lo discursivamente seria um sacrilégio: é possível sentir nele corporalmente o momento de seu surgimento junto à moralidade. Corporalmente porque é o horror que surgiu praticamente ante a dor física insuportável à qual os indivíduos são expostos mesmo depois que a individualidade, enquanto forma de reflexão espiritual, se prepara para desaparecer. A moral só sobrevive em um motivo materialista sem disfarces. O curso da história conduz necessariamente ao materialismo aquilo que tradicionalmente foi o seu oposto imediato, a metafísica. (ADORNO, 2009, p. 302-303)

E, finalizo esta exposição com uma última citação da Dialética negativa: "Os interesses metafísicos dos homens necessitam de uma percepção não reduzida de seus interesses materiais. Enquanto esses interesses permanecem velados para eles, eles vivem sob o véu de Maia" (2009, p. 330). 
NEGATIVE DIALECTICS: TENSIONS BETWEEN PHILOSOPHY AND METAPHYSICS

ABSTRACT: The aim of this essay is to examine the concept of metaphysics developed by Theodor Adorno, in "Part III, Models" of his book Negative Dialectics. Firstly, it presents an approach to the category of negative dialectics, based on dialogue with Hegel while, at the same time, in opposition to his idealist dialectics, uses as a reference the assumption that only the concept can overcome the concept and thus approximate the non-conceptual. Then, as in the previous case, the text indicates that Adorno, in constructing a new metaphysics, does not abandon the specific categories which had historically given his work sustainability. However, he inverts them in his direction: negative metaphysics migrates to micrology, to "the scum of the world of phenomena". Key concepts of traditional metaphysics - essence, infinitude and depth - in the context of the primacy of the object over the subject, now return to "the things of men". The text also shows that Adorno, instigated by the observation of Simmel who, from an idealistic perspective, says: how amazing it is that the sufferings of humanity are so little seen in the history of philosophy, turns to an analysis of pain, grievances and genocide, sad realities which characterize the history of humanity in times of capitalist societies.

KEYwORDs: Negative Dialectics. Metaphysics. Theodor Adorno. Friedrich Hegel.

\section{DIALÉCTICA NEGATIVA: FILOSOFÍA Y METAFÍSICA - TENSIONES}

Resumen: Este ensayo tiene por objetivo analizar el concepto de la metafísica desarrollado por Theodor Adorno, en la "Parte III, Modelos" de su libro Dialéctica negativa. Inicialmente, se ocupa en abordar la categoría de dialéctica negativa, que se construye en el diálogo con Hegel y, al mismo tiempo, en contraste con su dialéctica idealista, tomando como referencia el principio de que sólo el concepto puede superar al conceptoy, de esta forma, aproximarse de lo no conceptual. El texto continúa, al igual que el proceso anterior, exponiendo que el frankfurtiano, en la construcción de una nueva metafísica, no abandona a las categorías específicas que históricamente le dieron sostenibilidad, sin embargo, las invierte en la tendencia de su dirección: la metafísica negativa emigra hacia la micrología, para "la escoria del mundo de los fenómenos". Conceptos claves de la metafísica tradicional - esencia, infinitud y profundidad en el contexto de la primacía del objeto sobre el sujeto, ahora se vuelven hacia las "cosas de los hombres". El ensayo muestra, además, que Adorno, siendo instigado por la observación de Simmel de cómo es espantoso y cuán poco son observados los sufrimientos de la humanidad en la historia de la filosofía, construida en una perspectiva idealista, se vuelve al análisis del dolor, del llanto, del genocidio, tristes realidades que caracterizan la historia de los hombres en tiempos de las sociedades capitalistas.

Palabras claves: Dialéctica negativa. Metafísica. Theodor Adorno. Friedrich Hegel. 


\section{NOTA}

1. "Adequação da coisa com o intelecto".

\section{REFERÊNCIAS}

ADORNO, T.W. Minima moralia: reflexões a partir da vida danificada. Trad. Luiz Eduardo Bicca. São Paulo: Ática, 1992.

. Crítica cultural e sociedade. In: Prismas: crítica cultural e sociedade. Trad. Augustin Wernet e Jorge Mattos Brito de Almeida. São Paulo: Ática, 1998. p. 7-26.

. Atualidade da filosofia. Trad. Bruno Pucci e Newton Ramos-de-Oliveira. Piracicaba: UNIMEP, 2000. (Publ. Interna).

. A arte é alegre. In: PUCCI, B.; Zuin, A. A. S.; RAMOS-de-OLIVIERA, N. (Org.). Teoria crítica, estética e educação. Piracicaba: Editora da Unimep, 2001. p. 11-18.

. Educação após Auschwitz. In: Educação e emancipação. Trad. Wolfgang Leo Maar. 3. ed. Rio de Janeiro: Paz e Terra, 2003. p. 119-138.

. Dialética negativa. Trad. Marco Antônio Casanova. São Paulo: Edunesp, 2009.

. Teoria da semiformação. In: PUCCI, B.; LASTÓRIA, L. A. C. N.; ZUIN, A. A. S. Teoria crítica e inconformismo: novas perspectivas de pesquisa.Trad. Newton Ramos-de-Oliveira. Campinas: Autores Associados, 2010.

HORKHEIMER, M; ADORNO, T. W. Dialética do esclarecimento: fragmentos filosóficos. Trad. Guido Antônio de Almeida. Rio de Janeiro: Jorge Zahar, 1985.

PUCCI, B. A dialética negativa enquanto metodologia de pesquisa em educação: atualidades. Revista e-curriculum, São Paulo, v. 8, n. 1, abr. 2012a.

.Theodor Adorno e a frieza burguesa em tempos de tecnologias digitais. São Leopoldo, RS: Cadernos IHU ideias, ano 10, n. 172, 2012 b.

BRUNO PuCCl é professor titular do PPGE/UNIMEP; pesquisador do CNPq; coordenador do Grupo de Pesquisa Teoria Crítica e Educação. E-mail:puccibru@gmail.com 